\title{
SURGERY FOR AN IMPROVED MULTIPLE-CHANNEL COCHLEAR IMPLANT
}

\author{
Graeme M. Clark, PhD, Fracs \\ BRian C. PyMAN, DLO, FRACS \\ QuENTIN E. BAILEY, DLO, FRACS \\ Robert L. Webb, DLO, FRACS \\ Robert K. SHEPHERD, BSC
}

East Mflbourne, Australia

An improved multiple-channel cochlear implant has been developed. The titanium container with enclosed electronics, the receiver coil. and the connector are embedded in medical-grade Silastic. The upper half of the implant has a diameter of $35 \mathrm{~mm}$ and a height of 4.5 $\mathrm{mm}$. and the kwer half a diameter of $23 \mathrm{~mm}$ and a height of $5 \mathrm{~mm}$. The electrode array has also been designed to reduce the possibility of breakage due to repcated movements over many vears. The surgery involves drilling a bed in the mastoid bone for the receiver-stimulator, and fixing the proximal electrode under the mastoid cortex. Centle insertion of the electrode array through the round window and along the seala tympani is achieved with a specially designed nicroclaw

\section{INTRODUCTION}

In 1978 and 1979 three of our profoundly-totally deaf patients had multiple-channel cochlear implant operations.' Two of these patients had extensive psychophysical tests. These showed that they could perceive different pitch sensations which varied according to the site of stimulation. ${ }^{2}$ This led to the development of a speech-processing strategy where the voicing frequency and energy, and the frequency and energy of the second formant, were extracted. The parameters for voicing determined the rate of stimulation for each electrode, and the second formant the site of the electrode stimulated and current level. ${ }^{3}$ In the third patient it was only possible to carry out a limited number of psychophysical tests, but they also showed that the perceived pitch varied according to the site of stimulation. Further tests on this patient were prevented by a device failure within a few months of implantation.

Although it was established that the implantable receiver-stimulator and wearable speech-processor could provide significant help with communication, ${ }^{4,5}$ it was considered desirable to develop an improved version for a number of reasons. First, the device failure in the third patient indicated the need for a revised design. Second, the psychophysical tests showed that improvements in speech-processing would be possible with greater flexibility in the receiver-stimulator electronics. ${ }^{\circ}$ Third, the device was too large for convenient placement in some patients. Its dimensions were length $42 \mathrm{~mm}$, width 32 $\mathrm{mm}$, height of connector section $8.5 \mathrm{~mm}$, and height of receiver-stimulator unit $13 \mathrm{~mm} .{ }^{1}$

To meet these needs a new multiple-channel cochlear implant has been developed by Nucleus
Limited in conjunction with the Department of Otolaryngology at the University of Melbourne. The improved receiver-stimulator is shown in Fig 1. The electronics are enclosed in a cylindrical hermetically-sealed titanium container with a diameter of $20 \mathrm{~mm}$ and height of $5 \mathrm{~mm}$. The connector and 22-electrode array is attached to the undersurface of the receiver-stimulator. The complete unit with receiver coil is embedded in medical grade Silastic and has a mushroom shape. The upper half or cap has a diameter of $35 \mathrm{~mm}$ and a height of $4.5 \mathrm{~mm}$, while the lower half or stalk has a diameter of 23 $\mathrm{mm}$, and a height of $5 \mathrm{~mm}$.

As indicated, one of the reasons for developing a new receiver-stimulator was device failure, and it was subsequently learned, following the explantation of a package, that the main failure mode was breakage of electrodes at the point where they emerged from the receiver-stimulator. This was a point of transition from an immobile package to mobile electrode, and was an area of stress concentration. The failure was precipitated by the third patient who had a predisposition to rub over the

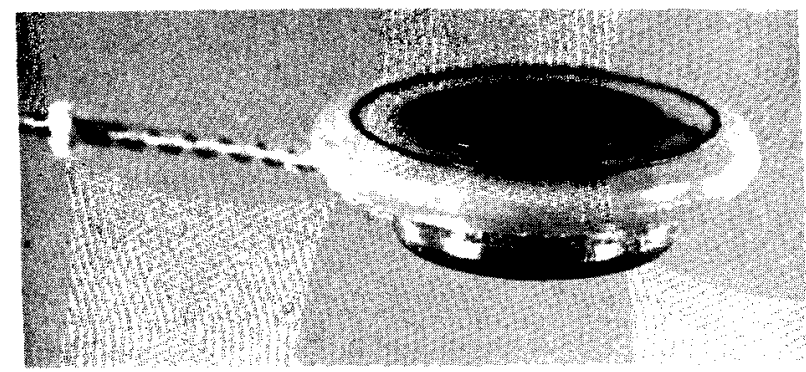

Fig 1. Receiver-stimulator package showing receiver coil, titanium container for electronics and connector, and proximal electrode array.

From the Department of Otolaryngology, University of Melbourne, The Royal Victorian Eye and Ear Hospital, East Melbourne. This study was financed by a public interest grant from the Commonwealth Government of Australia to Nucleus Limited. Lane Cove. Sydney.

REPRINTS - Dr G. M. Clark, Department of Otolaryngology, University of Melbourne, The Royal Victorian Eye \& Ear Hospital, 32 Gisborne St, East Melbourne. Vic 3002. Australia. 

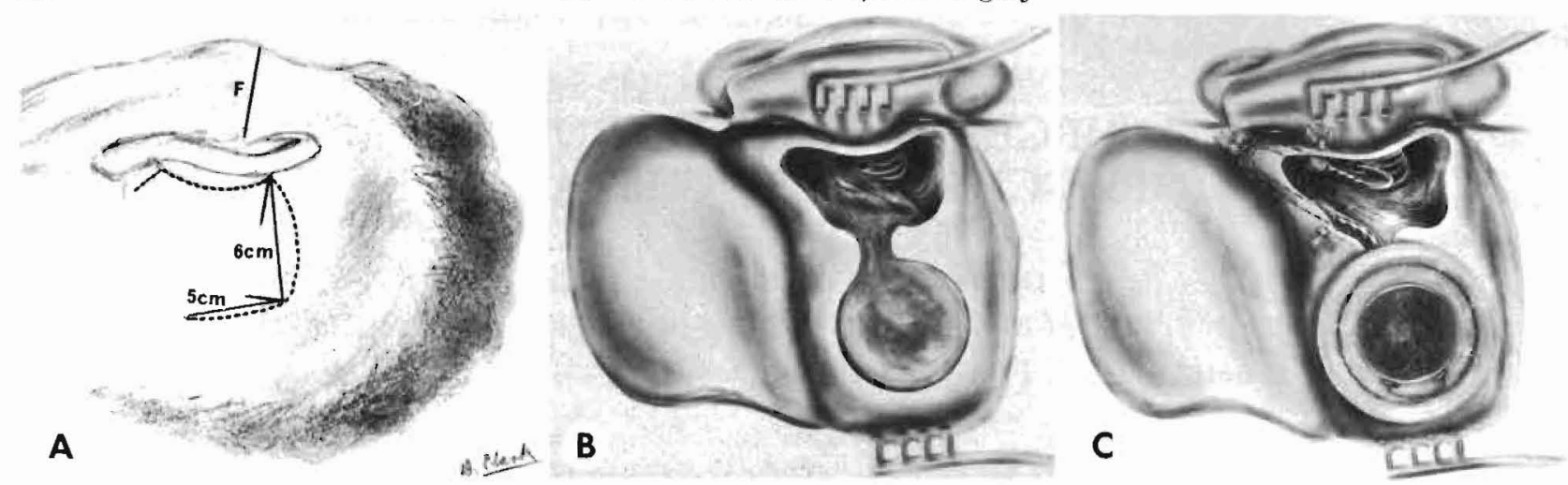

Fig 2. Surgical procedure. A) Diagram of incision used for multiple-channel cochlear implants. F - Frankfurt's plane. B) Bed created for receiver-stimulator, and mastoid cortical overhang left to protect proximal electrode. C) Receiver-stimulator in its bed, proximal electrode beneath mastoid cortex, and distal electrode entering round window through posterior tympanotomy.

area frequently each day. A failure also occurred in the second patient after many months of testing, and was contributed to by the side arm of his glasses pressing over the point where the electrodes emerged from the package. In both the second and third patients the receiver-stimulator had no connector, and the electrode exit-point lay behind the pinna and was, therefore, more readily exposed to movements transmitted from outside. On the other hand, the first patient had a connector, and this was placed in a Silastic 382 mold in the mastoid bowl deep to the pinna, resulting in greater protection of the electrode exit-point. In this patient's case, the receiverstimuator has functioned since Aug 1, 1978, and only recently have there been electrode failures.

This experience serves to emphasize the importance of preventing electrode breakage, and a great deal of consideration has been given to this in the design of the new electrode array and its surgical placement. The electrode array, after it emerges from the package, is now thicker and more robust. At surgery it is fixed in a tunnel under the mastoid cortex to reduce movements being transmitted to the thinner section of the electrode lying in the mastoid bowl and entering the cochlea through the round window. This experience is also a reminder not to implant large numbers of patients until the possibility of device failures due to design weaknesses is reduced to a minimum. Devices should, of course, be thoroughly evaluated in vitro and in animals before human implantation. There are, however, other factors such as human behavior and anatomy that cannot be adequately simulated. Hence the need for small patient studies before wider application.

The present paper discusses the surgery involved in implanting the improved receiver-stimulator, and is an extension of the principles outlined previously for implanting multiple-channel hearing prostheses.' It also involves the same detailed attention to the prevention of infection reported earlier by the University of Melbourne implant group. ${ }^{7}$

\section{SURGICAL PROCEDURE}

An incision is made through the skin, subcutaneous tissue, and superficial fascia behind the pinna. As shown in Fig $2 \mathrm{~A}$, it commences at the mastoid tip, passes forward to the postaural sulcus, and around the sulcus to the top of the external ear. It then arches posterosuperiorly at an angle of $15^{\circ}$ to Frankfurt's plane (a plane through the inferior margin of the orbit and superior margin of the external auditory meatus) for a distance of $6 \mathrm{~cm}$. It is important to round the anterosuperior corner in order not to compromise the blood supply to this area. Finally, the incision arches posteroinferiorly for a distance of $5 \mathrm{~cm}$ at an angle of $15^{\circ}$ to the coronal plane. These flap dimensions allow the receiverstimulator to be placed so that there is at least $1 \mathrm{~cm}$ between its outer rim and the anterior and posterior limbs of the incision. The flap is then elevated and dissected from the underlying deep fascia and periosteum. The C-shaped flap recommended by House ${ }^{8}$ would also be suitable.

A flap of deep fascia and periosteum, which is anteriorly based, is then fashioned by cutting down to bone $1 \mathrm{~cm}$ inside the borders of the exposed area. The tissue is elevated and the dissection extended into the lateral third of the external auditory canal.

It is now not considered desirable to elevate the tympanic membrane and expose the middle ear as a routine procedure, as it increases the risk of tearing the canal skin and providing a path for infection to enter the operative area. Disease that may preclude surgery can normally be excluded by history, otoscopy, tympanometry, and polytome $x$-ray study. It is also not necessary to see if a round window is present. In many cases it is difficult to visualize from a meatal approach, and recent personal experience has shown that, even if it is absent or obliterated, a new window, and if necessary proximal basal turn, can be drilled to allow the insertion of a multiple-electrode array.

The mastoid antrum is opened and the lateral semicircular canal and short process of the incus ex- 


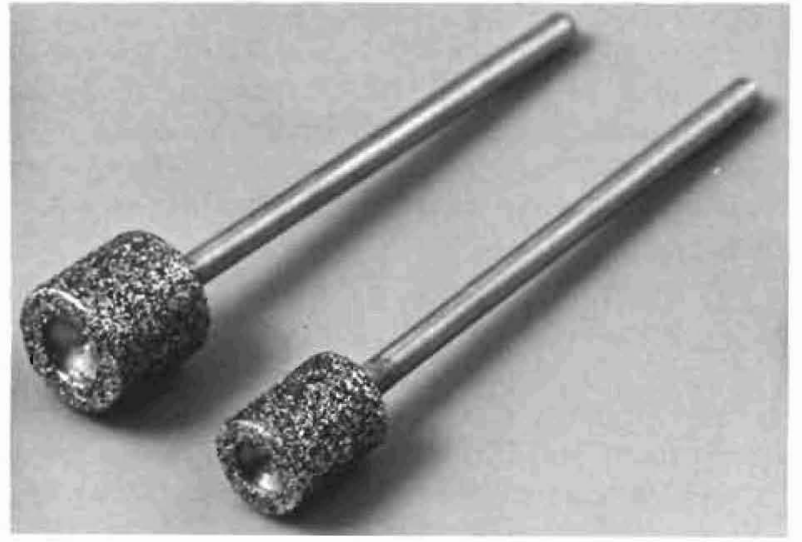

Fig 3. Diamond paste milling burr used to create bed for receiver-stimulator. $(x 2.5)$

posed, as these are important landmarks for identifying the facial nerve during the posterior tympanotomy. In carrying out the posterior tympanotomy the posterior bony meatal wall is thinned, and the cellular system anterior and lateral to the sigmoid sinus is removed. It is important to leave the cortex over the inferior part of the mastoid as this will protect the electrode passing from the receiver-stimulator package to the round window. The entry into the middle ear is then made using a diamond paste burr (Fig 3). Prior to this procedure it is very desirable to identify the vertical segment of the facial nerve from a point just below the lateral semicircular canal inferiorly for a distance of about $5 \mathrm{~mm}$. This will help reduce the chances of nerve injury if there are variations in anatomy and difficulties in exposing the round window. A thin layer of bone should be left lateral to the facial nerve as the shank of the burr may need to rest on this area while drilling the bone overhanging the round window niche. When access to the middle ear is difficult, the posterior external canal wall should be thinned in a medial direction and the annulus of the tympanic membrane and the chorda tympani nerve exposed. An anteriorly or laterally directed facial nerve frequently limits the inferior boundary, and it should be skeletonized at this point.

The cells of the mastoid protuberance are then exenterated by the assistant surgeon from the head end of the table. As shown in Fig 2B, the cortex over the anterior, inferior, and posterior parts is preserved, and a groove drilled beneath the overhang to allow the electrode lead to lie snugly underneath the bone. A bed is created for the stalk section of the receiver-stimulator package with its center lying so that there is a distance of $10 \mathrm{~mm}$ between the postaural sulcus, and the edge of the receiver-stimulator cap. This space is needed to allow the fitting of the external coil unit and the wearing of glasses. The package bed should not be sited too high as a lowlying dura may restrict its depth. Alternatively, it should not be placed too low as this will produce a prominent lower edge and the possibility of the cervical muscles pulling on the package.

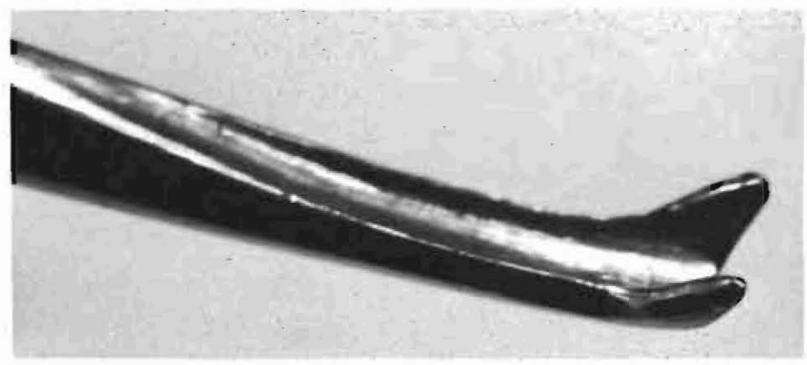

Fig 4. Specially-designed claw to facilitate gentle insertion of electrode array along scala tympani. (x30)

The bed is begun with a large cutting burr by saucerizing the area down to the sigmoid sinus. It is completed by using a diamond paste milling burr. This burr has the central section removed from the drill base to prevent bone dust clogging this face (Fig 3). It is used by applying lateral pressure around the periphery of the excavation, and this enables a clearly defined circular area with a flat floor to be drilled speedily and with precision. Finally, a groove for the electrode is then made from the anteroinferior section of the receiverstimulator bed to the groove previously created beneath the mastoid cortex.

A dummy implant is placed in position to ensure that the package will be stable in its bed and that the proximal electrode will sit correctly in its groove. Holes are then drilled for three Dacron mesh stays to fix the proximal electrode in place after the cochlear array has been inserted into the basal turn of the scala tympani. These holes are placed in the mastoid cortex anteriorly, at the mastoid tip, and overlying the electrode groove near the package bed.

Although the redesigned proximal electrode has passed flexing tests which show that the chance of electrode breakage is small, its fixation is important to protect the distal electrode from movements transmitted from outside and following acceleration and deceleration of the head.

The next stage of the procedure is to create additional flaps from the temporalis fascia and occipital periosteum that can be used later to provide, with the previously created anterior flap, complete cover of the receiver-stimulator package. Before proceeding with the final stage of the operation it is necessary to ensure complete hemostasis; cautery should not be used when the receiver-stimulator is in place, as it may induce electronic failure or harmful effects on the cochlea via the implanted electrode.

A swab is taken from the round window region for bacteriological examination. This is necessary in case any upper respiratory tract organisms have very recently infected the middle ear, in which case their nature and antibiotic sensitivities are required when choosing the correct postoperative antibiotic 


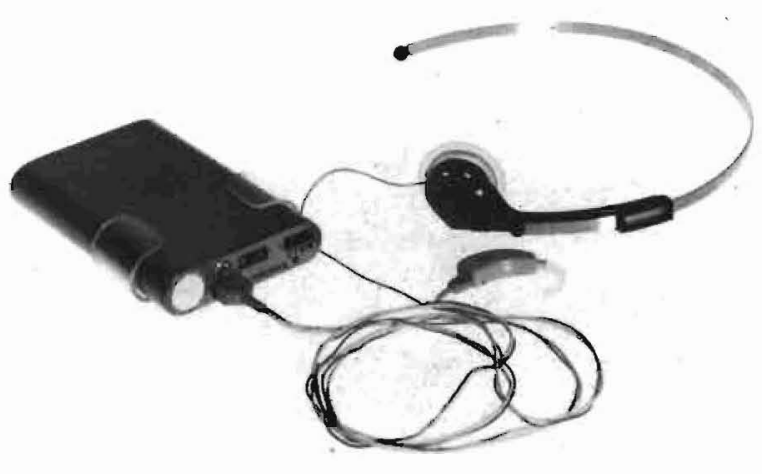

Fig 5. Wearable speech-processor, transmitter coil, and microphone for multiple-channel cochlear inlpant. Dimensions of speech-processor: height - $110 \mathrm{~mm}$, width $73 \mathrm{~mm}$, and depth $-19 \mathrm{~mm}$.

regime. Ampiclox solution $(0.1 \%$ ampicillin and $0.05 \%$ cloxacillin in normal saline) is then instilled into the middle ear. Ampicillin is used because it has a broad spectrum of antibacterial activity and cloxacillin because it is a potent inhibitor of penicillinase-producing staphylocci which may contaminate the area through the incision.

The bone overhanging the round window niche is drilled away to expose the secondary tympanic membrane. As the membrane is in two planes with the posterosuperior third lying superficially, special care is needed when drilling in this region. The membrane is incised half way around its perimeter on the side away from the basilar membrane. If an adequate view cannot be obtained along the basal turn, the opening can be enlarged anteroinferiorly with a $0.6-\mathrm{mm}$ diamond paste drill. The electrode is then gently inserted using the specially-designed claw shown in Fig 4. This claw fits neatly around part of the circumference of the electrode array. It also has a bend in the shank $15 \mathrm{~mm}$ from the end. This allows the instrument to be held in a steady position, with adequate vision during the electrode insertion. Trauma to the spiral lamina and basilar membrane is also minimized if the claw is used to apply a force which is directed away from these structures. The insertion can also be facilitated by using the other hand to rotate the package and electrode during the procedure. Finally, an autograft is placed in the region of the round window membrane to induce an early and adequate seal in this area.

The electrode is steadied by the surgeon and the assistant ties the previously placed Dacron mesh stays which hold the proximal electrode in its protective groove. The receiver-stimulator is then placed in its bed (Fig 2C). The wound is irrigated with $0.1 \%$ ampicillin and $0.05 \%$ doxacillin (Ampiclox) solution. The fascial and periosteum flaps are then brought together to completely cover the implanted package and are sutured with a monofilament material. The skin is closed, Gelfoam soaked in a local antibiotic solution is packed in the external auditory meatus, and a firm pressure dressing applied to the operative side.

\section{POSTOPERATIVE REHABILITATION}

The patients are usually free of any giddiness postoperatively and are allowed out of bed the day after the operation. They normally leave the hospital six days later, and the stitches are removed on the tenth postoperative day. The implant produces a swelling, but this is not particularly noticeable.

The first test session commences 2 or 3 weeks postoperatively. The patient's threshold, comfortable loudness level, dynamic range, and loudness scaling for each bipolar electrode pair are determined as well as the pitch ranking for all electrodes. A diagnostic programming unit is used to place the psychophysical parameters into the erasable programmable read-only memory (EPROM) of the wearable speech-processor. Normally the psychophysical tests and programming of the speech processor can be accomplished by the end of the first or second test session. The patient is then free to take home the wearable speech processor (Fig 5) and commence rehabilitation.

ACKNOWLEDGMENTS - We thank the medical director and staff of the Royal Victorian Eve and Ear Hospital for their help and cooperation: Drs D. W. Marty and S. Kleid for their help in the medical management of patients; Mrs D. M. Clark and Mr J. Salter for medical artwork: Mrs E. Utton for the typing: and $\mathrm{Mr}$ J. Scrimgeour, Mrs J. $\mathrm{Ng}$ and Mrs C. Grant for the photography:

\section{REFERENCES}

1. Clark CM, Pyman BC, Bailey QR. The surgery for multiple-electrode cochlear implantations. J Laryngol Otol 1979; 93:215-23.

2. Tong YC, Black RC, Clark GM, Forster IC, Millar JB, O Loughlin BJ. A preliminary report on a multiple-channel cochlear implant operation. J Laryngol Otol 1979; 93:679-95.

3. Tong YC, Clark CM, Seligman PM, Patrick JF. Speech processing for a multiple-electrode cochlear implant hearing prosthesis. J Acoust Soc Am 1980; 68:1897-9.

4. Clark GM, Tong YC. A multiple-channel cochlear implant. A summary of results for two patients. Arch Otolaryngol $1982 ; 108: 214-7$
5. Clark GM, Tong YC, Dowell RC. Comparison of two cochlear implant speech-processing strategies. Ann Otol Rhinol Laryngol 1984: 93:12т-31.

6. Tong YC, Dowell RC, Blamey PJ. Clark CM. Two component hearing sensations produced by two-electrode stimulation in the cochlea of a totally deaf patient. Science 1983; 219:993-4.

7. Clark GM, Pyman BC, Pavillard RE. A protocol for the prevention of infection in cochlear implant surgery. J Laryngol Otol 1980; $94: 13 \pi T-86$

8. House WF. Surgical considerations in cochlear implantation. Ann Otol Rhinol Laryngol 1982; 91 (suppl 91):15-20. 


\section{University Library}

\section{- M M I N E R VA A gateway to Melbourne's research publications}

Minerva Access is the Institutional Repository of The University of Melbourne

Author/s:

Clark, Graeme M.;Pyman, Brian C.;Webb, Robert L.;Bailey, Quentin E.;Shepherd, Robert K.

Title:

Surgery for an improved multiple-channel cochlear implant

Date:

1984

Citation:

Clark, G. M., Pyman, B. C., Webb, R. L., Bailey, Q. E., \& Shepherd, R. K. (1984). Surgery for an improved multiple-channel cochlear implant. Annals of Otology, Rhinology and Laryngology, 93(3), 204-207.

Persistent Link:

http://hdl.handle.net/11343/27198 